\section{Fatal aortogastric fistula following fully covered metal stent placement for refractory esophageal stricture}
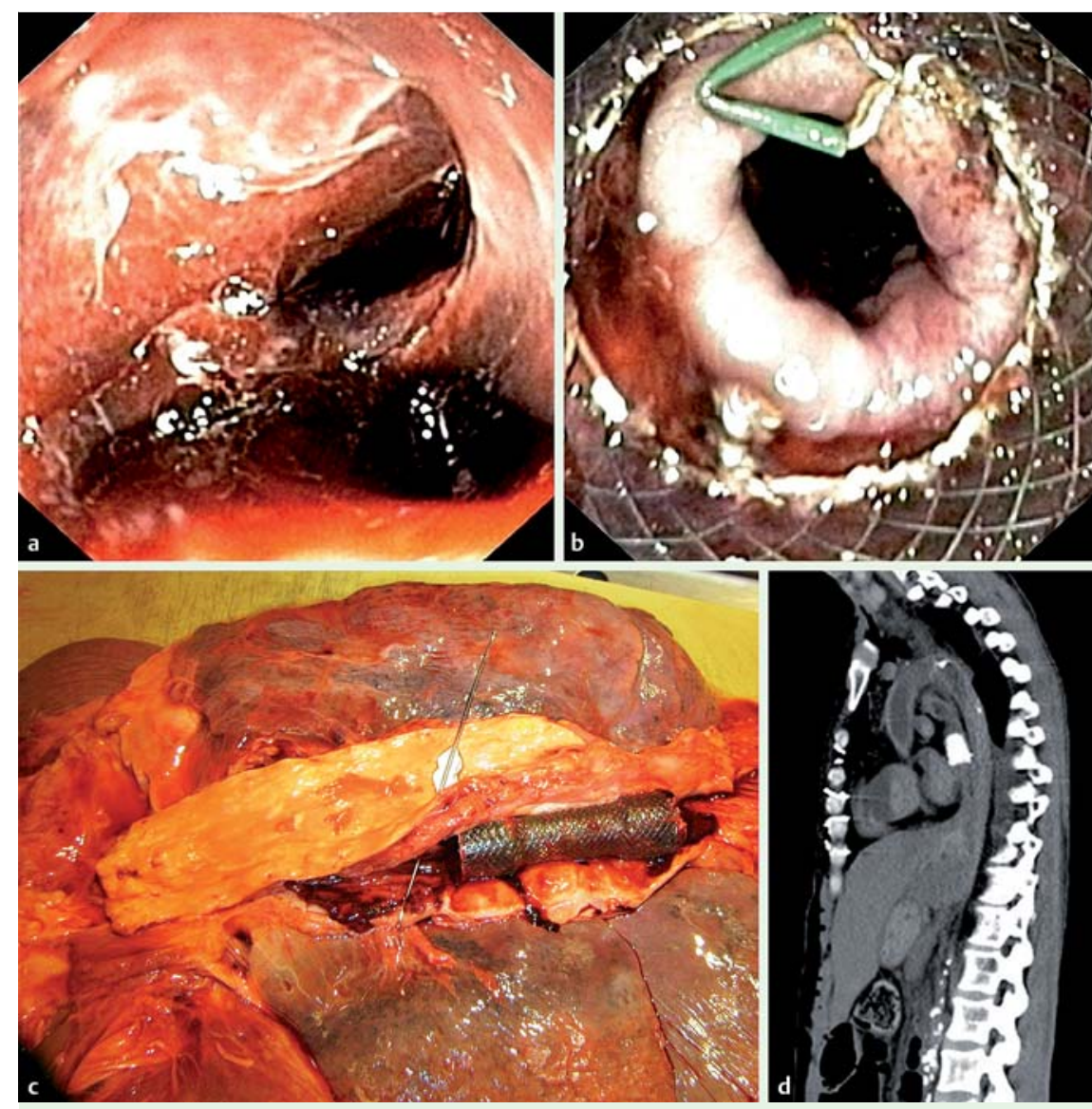

Fig. 1 Emergency upper endoscopy and full-body computed tomography were performed following massive hematemesis and hemodynamic instability 3 weeks after placement of a fully covered stent. a Visualization of the anastomosis. b Distal part of the fully covered stent resting on the pylorus (migrated stent). c Post-mortem autopsy: aorto-gastric fistula located at the distal end of the fully covered stent (metal arrow). d Post-mortem full-body scan showing close contact between the stent and the aorta.

A 45-year-old woman with a history of systemic sclerosis presented with a postanastomotic gastric tube stenosis 1 year after esophagus resection and gastric tube interposition for a ypT3N1M0 adenocarcinoma of the esophagus. She was also treated with neo-adjuvant chemoradiation therapy [1]. Endoscopy identified a post-anastomotic esophageal stenosis extending from $24 \mathrm{~cm}$ to $32 \mathrm{~cm}$ aborally. She had shown only a limited response to 23 Savary dilations and one balloon dilation in 9 months. We therefore decided to use an $18 \times 12 \mathrm{~cm}$ fully covered metal stent (Evolution; Cook Medical Inc., Bloomington, Indiana, USA) across the stenosis. the patient did not show any cardiac activity in spite of direct cardiac massage and chemical resuscitation, and she died during surgery. A post-mortem full-body computed tomography scan and autopsy revealed an aortogastric fistula on the downwards -migrated distal part of the esophageal stent ( $\mathbf{F i g} \mathbf{1} \mathbf{1}$, c).

An aorto-esophageal fistula (AEF) is an infrequent, but mostly fatal complication after esophagectomy [2,3]. Thoracic aortic aneurysms are the most common cause of AEF; further causes include foreign body ingestion, trauma (usually iatrogenic), carcinoma or, rarely, tuberculous aortitis [3]. The literature on esophageal stentrelated AEF is scarce, and can be classified as follows.

1. Anastomic-aortic fistula

- after anastomotical leakage and esophageal stent placement (aortic pressure and local inflammation) [3]

- after anastomotical stenosis and stent placement (aortic pressure and possible local perforation) $[4,5]$

2. Benign esophageal stricture-aortic fistula after stent placement (aortic pressure and possible local perforation) [6]

3. Direct stent perforation-induced aortic fistula

- non-migrated stent [7]

$\checkmark$ migrated stent (the current case).

Siersema et al. reported the first case of an AEF caused by proximal stent perforation in a patient with inoperable squamouscell carcinoma [7]. A gastric-aortic fistula caused by perforation due to a migrated distal fully covered stent in an esophagectomized patient with a benign anastomotical stensosis has not been reported previously. Direct pressure-related perforation of the gastric wall by a fully covered stent is the possible mechanism in the current case and raises questions about the design of fully covered stents and indications for their use. Radiotherapy and chemotherapy have been described as possible risk factors for developing complications after esophageal stent placement [4]. Further research on this matter is warranted following the recent publication of the CROSS study results [1] and the fact that combined chemoradiotherapy is becoming the gold standard approach for patients with esophageal adenocarcinoma.

\section{Endoscopy_UCTN_Code_CPL_1AH_2AD}

Competing interests: None 


\section{E. J. M. van Geenen', N. C. M. Visser ${ }^{2}$, J. J. Bonenkamp ${ }^{3}$}

${ }^{1}$ Department of Gastroenterology and Hepatology, St. Radboud University Medical Center, Nijmegen, The Netherlands

2 Department of Pathology, St. Radboud University Medical Center, Nijmegen, The Netherlands

${ }^{3}$ Department of Surgery, St. Radboud University Medical Center, Nijmegen, The Netherlands

\section{References}

1 van Hagen P, Hulshof MC, van Lanschot JJ et al., on behalf of the CROSS Group. Preoperative chemoradiotherapy for esophageal or junctional cancer. N Engl J Med 2012; 366: 2074-2084

2 Okita R, Mukaida H, Takiyama $W$ et al. Successful surgical treatment of aortoesopha- geal fistula after esophagectomy. Ann Thorac Surg 2005; 79: 1059-1061

3 Byard RW. Lethal aorto-oesophageal fistula - characteristic features and aetiology. J Forensic Leg Med 2013; 20: 164-168

4 Rogart J, Greenwald A, Rossi F et al. Aortoesophageal fistula following Polyflex stent placement for refractory benign esophageal stricture. Endoscopy 2007; 39 (Suppl. 01): E321-322

5 Schweigert M, Dubecz A, Stadlhuber RJ et al. Risk of stentrelated aortic erosion after endoscopic stent insertion for intrathoracic anastomotic leaks after esophagectomy. Ann Thorac Surg 2011; 92: 513-518

6 Unosawa S, Hata M, Sezai A et al. Surgical treatment of an aortoesophageal fistula caused by stent implantation for esophageal stenosis: report of a case. Surg Today 2008; 38: $62-64$

7 Siersema PD, Tan TG, Sutorius FF et al. Massive hemorrhage caused by a perforating Gianturco-Z stent resulting in an aortoesophageal fistula. Endoscopy 1997; 29: 416-420
Bibliography

DOI http://dx.doi.org/

10.1055/s-0033-1344561

Endoscopy 2014; 46: E16-E17

(c) Georg Thieme Verlag KG

Stuttgart · New York

ISSN 0013-726X

\section{Corresponding author}

\section{E. J. M. van Geenen, MD}

Department of Gastroenterology and Hepatology St. Raboud University Medical Center Geert Grooteplein-Zuid 22

Nijmegen

Gelderland 6525 GA

The Netherlands

Fax: +31-24-3540103

e.vangeenen@mdl.umcn.nl 